\begin{tabular}{l|l} 
Denise Duarte & LABAUT - LABORATÓRIO DE \\
& CONFORTO AMBIENTAL E \\
& EFICIÊNCIA ENERGÉTICA \\
& DEPARTAMENTO DE TECNOLOGIA DA \\
& ARQUITETURA DA FAUUSP
\end{tabular}

\title{
I. Apresentação
}

O Laboratório de Conforto Ambiental e Eficiência Energética do Departamento de Tecnologia da Arquitetura da FAUUSP - LABAUT foi criado em 1999 e é inscrito no CNPq como grupo de pesquisa desde junho de 2002.

O LABAUT atua nas seguintes áreas:

- Conforto térmico das edificações e do espaço urbano;

- conforto luminoso natural e artificial das edificações e do espaço urbano;

- conforto acústico das edificações e do espaço urbano;

- ergonomia aplicada às edificações, ao espaço urbano, ao mobiliário e equipamentos;

- eficiência energética das edificações e do espaço urbano.

O LABAUT tem por objetivos:

- Desenvolver pesquisas voltadas para a implementação de linhas ainda não consolidadas dentro de sua área de atuação;

- fornecer suporte técnico ao desenvolvimento de pesquisas da graduação e pós-graduação, inclusive, de outras áreas, de outras unidades da USP ou de outras instituições;

- disponibilizar apoio laboratorial aos TFGs da FAUUSP;

- oferecer apoio a projetos de interesse social;

- atender às solicitações da indústria da construção e setores públicos afins.

\section{EQUiPE}

Atualmente a equipe docente do LABAUT é formada por: Márcia Peinado Alucci (coordenadora), Marcelo de Andrade Roméro (vice-coordenador), Joana Carla Soares Gonçalves, Denise Helena Silva Duarte e José Jorge Boueri Filho, todos em RDIDP, Anésia Barros Frota e Paulo Sérgio Scarazzato, em RTC, e José Fernando Cremonesi, em RTP. Também atuam como colaboradores os professores Reginaldo Luiz Nunes Ronconi, Ualfrido Del Carlo, Rosária Ono, Khaled Ghoubar e Fúlvio Vittorino (IPT). 


\section{INSTALAÇÕES, EQUIPAMENTOS E RECURSOS COMPUTACIONAIS}

Desde sua implantação o LABAUT vem ampliando a capacitação do laboratório com recursos provenientes de projetos didáticos apoiados pelas próreitorias de graduação e pós-graduação da USP, de projeto para aquisição de equipamentos, apoiado pela Fapesp, de projeto de pesquisa, apoiado pelo CNPq, e pela prestação de serviços.

Desde fevereiro de 2002 o LABAUT conta com um espaço físico de aproximadamente $110 \mathrm{~m}^{2}$, que inclui bancada de trabalho, heliodon, espaço para armazenamento e montagem de equipamentos, sala de reuniões e postos de trabalho da equipe. O LABAUT conta, atualmente, com os seguintes equipamentos:

- 15 kits-conforto que incluem luxímetro, decibelímetro, termohigrômetro, anemômetro, contador e bússola;

- 01 heliodon de régua para simulação de insolação em modelos físicos;

- 01 heliodon em arco (em construção), em parceria com o Laboratório de Modelos e Ensaios - LAME;

- 01 estação meteorológica portátil com sensores de temperatura, umidade, ventos e chuva;

- 01 estação meteorológica fixa com dois piranômetros (radiação direta e difusa), termohigrômetro, anemômetro (direção e velocidade de vento), pluviômetro (chuva);

- 01 luminancímetro;

- 02 Norsonic (equipamento de acústica para medida estatística de ruído L5, L10, L50, L90 e Leq, medidas com filtros A, B, C e D e linear, tempo de reverberação);

- $0101 \mathrm{~dB}$ (software de acústica com interfaces para isolamento por reciprocidade, análise estatística de ruído urbano, medida estatística de ruído $L 5$, L10, L50, L90 e Leq, medidas com filtros A, B, C e D e linear, tempo de reverberação);

- 02 confortímetros (temperatura operativa);

- 01 confortímetro/IBUTG;

- 01 termômetro infravermelho para medição de temperatura superficial;

- 02 registradores de temperatura, umidade e iluminância;

- câmera digital com lente grande angular para quantificação de fator de visão de céu;

- fotocélulas para ensaios em modelos físicos.

O LABAUT conta com a colaboração do Instituto de Pesquisas Tecnológicas do Estado de São Paulo - IPT - para uso do túnel de vento do Laboratório do Agrupamento de Vazão (Projeto temático Fapesp n. 98/15402-5), nas pesquisas vinculadas ao laboratório, e com a colaboração do Laboratório Nacional de Engenharia Civil - LNEC - Lisboa, Portugal, também para o uso do túnel de vento.

O LABAUT dispõe de softwares de simulação computacional e bancos de dados produzidos por integrantes da equipe, todos de domínio público e disponíveis no site da FAUUSP. São eles: Acústico 2.0, Fachada 1.5, Lux 1.0 e Chaminé 2.5 (Márcia Alucci); Humano 1.1 (Daniel Cóstola e Márcia Alucci); Climaticus 1.5 (Márcia Alucci e Gabriela Audi); Obstrução 1.0 (Rafael Brandão); Windoor (Fernando Cremonesi); CTCA (Tiago Ribeiro e Karin Marins); Banco de 
Dados de Acústica (Márcia Alucci e Paula Constante Santos); Banco de Dados de Vidros (Márcia Alucci, Celso Longo e Marcos Inoue); e DLN (Paulo Scarazzato). Dentre os softwares comerciais, as licenças recentemente adquiridas pelo LABAUT incluem Ecotect 5.2, Tas 8.5 e Fluent 6.1.2 (licença da Escola Politécnica da USP, em colaboração com a FAUUSP).

\section{Pesquisas da pós-graduação}

Nos últimos anos o grupo de estudos urbanos vem se fortalecendo e agregando novos resultados em relação à proteção do acesso ao sol, acesso à luz natural e consumo de energia em edifícios, em função dos arranjos urbanos. Crescem também os estudos das condições de ventilação urbana, em função do uso e ocupação do solo, e dos índices de conforto em ambientes externos, áreas essas ainda não consolidadas. Iniciam-se também os estudos de desempenho térmico e luminoso de membranas utilizadas para coberturas em áreas externas (projeto CNPq em andamento).

Em relação ao conforto e à eficiência energética nos edifícios, as pesquisas estão direcionadas para sistemas inovadores de fachadas, legislação relacionada ao consumo de energia, à reabilitação tecnológica de edifícios, ao conforto associado à produtividade do trabalho em edifícios de escritórios, ao estudo de indicadores de adequação ambiental de edifícios e ao desenvolvimento de metodologia para tratamento de dados de ventilação para projeto de edifícios.
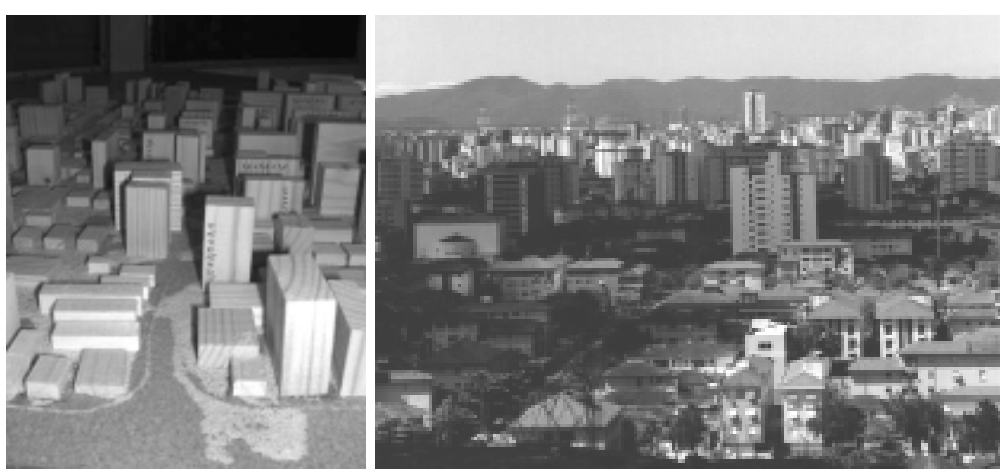

Figura 1 - Estudo de ventilação urbana em túnel de vento Fonte: Doutorado de Alessandra Prata

Figura 2 - Efeitos da obstrução, provocados pelo entorno no consumo de energia dos edifícios Fonte: Mestrado de Rafael Brandão

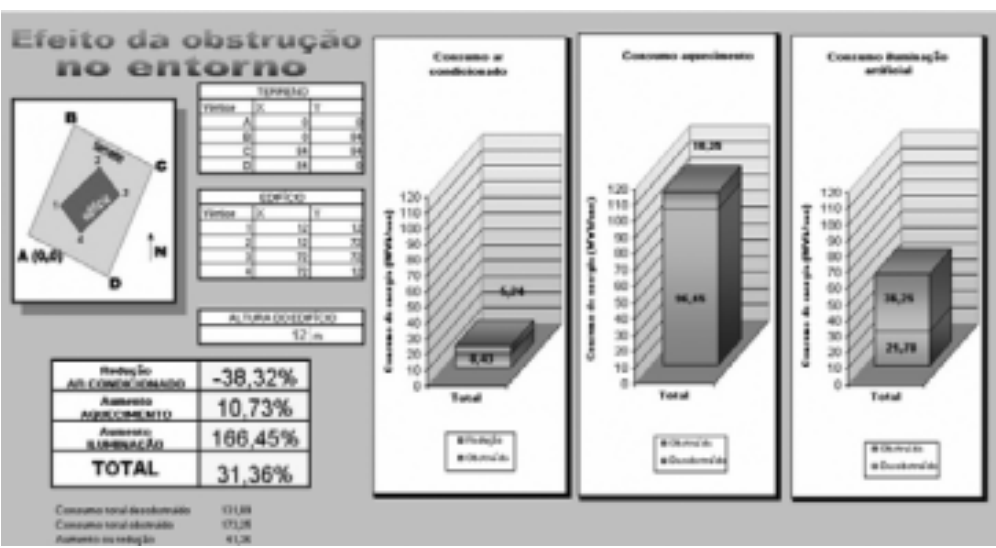


Tabela 1 - Pesquisas da pós-graduação vinculadas ao LABAUT

\begin{tabular}{|c|c|c|c|c|c|}
\hline Período & Aluno (a) & Orientador (a) & Título & Nivel & Bolsa \\
\hline $2001 / 04$ & Rafael Silva Brandão & Márcia Alucci & Acesso ao sol e à luz natural (concluida) & Mestrado & $\mathrm{CNPa}$ \\
\hline $2001 / 07$ & Norberto C. da Silva Moura & Márcia Alucci & $\begin{array}{l}\text { Segurança, eficiência energética e conforto visual em emboques de túneis rodoviários: so uçöes } \\
\text { arquitetônicas }\end{array}$ & Doutorado & Capes \\
\hline $2004 / 07$ & Leonardo M. Manteiro & Márcia Alucci & Uso de ferramentas computacionas para estuda de ventilação de edificics & Mestrado & Fapesp \\
\hline $2004 / 08$ & Tiago Randuz & Márcia Alucci & Conforto témic o de estáclios esportivos & Doutorado & - \\
\hline $2001 / 04$ & \begin{tabular}{|l|}
$\begin{array}{l}\text { Valéria Cristina D. L. } \\
\text { Resende }\end{array}$ \\
\end{tabular} & Márcia Alucci & $\begin{array}{l}\text { O aproveitamenta da iluminaçāo natural em edifícios universitárias, visando à conservaçāo de } \\
\text { energia elétrica e ao conforto luminoso }\end{array}$ & Mestrado & - \\
\hline $2004 / 07$ & Daniel Cósto la & Márcia Alucci & Desenvolvimento de software para avaliação de ventilaçäo interna de edifícios & Mestrado & $\mathrm{CNPq}$ \\
\hline $2000 / 03$ & Antôn o Gil da Silva Andrade & Márcia Alucci & Alta tecnologia: a arquitetura de 1970 a 2000 (concluída) & Mestrado & - \\
\hline $2003 / 07$ & Antôn o Gil da Si lva Andrade & Márcia Alucci & Sistemas construtivos utilizados em edificios esportivos & Doutorado & - \\
\hline $2001 / 05$ & Alessandra Rodrigues Prata & Anésia Frota & $\begin{array}{l}\text { D mensionamento do impacto da altura de ediff́cios nas condiçöes de ventilaçăo natural do } \\
\text { meio urbano, simulado e m túnel de vento - }- \text { caso da cidade de Santos/SP }\end{array}$ & Doutorado & Fapesp \\
\hline $2004 / 07$ & Cintia Mara de Figueiredo & Anésia Frota & Estudo de fachadas de ed ificios comerciais & Mestrado & - \\
\hline $2004 / 07$ & Cecilia Mattos Muller & Anésia Frota & $\begin{array}{l}\text { Procedimentos de medição para aval iação do c omportamento térmico de edificaçōes } \\
\text { construídas sem sistemas atvos de condicionamento }\end{array}$ & Mestrado & - \\
\hline $2001 / 05$ & Lúcia Dilonardo & Anésia Frota & Eficięncia energética de edificios camercizis: uma abordagem ecınômica & Doutorado & - \\
\hline $2000 / 04$ & Ana V rginia C. Sampaio & Anésia Frota & A valorizaçāo do conforto amb ental na elaboraçāo dos projetos de ambientes hospitalares & Doutorado & - \\
\hline 2000104 & Victor Aramis Berti & Anésia Frota & Ventilação em áticos & Doutorado & - \\
\hline 2004107 & Thiago Zaldini Hernandes & Denise Duarte & $\begin{array}{l}\text { Indicadores de sustenta bilidade } \text { LEED }^{T M} \text {, BREEAM }{ }^{\top M} \text { e SPeAR: análise crítica de escala de } \\
\text { valores, propostas e aplicabilidade para a realidade nacional }\end{array}$ & Mestrado & - \\
\hline $2003 / 06$ & Anna Christina Miana & $\begin{array}{l}\text { Rosana C. Assis } \\
\text { (EESC/USP) }\end{array}$ & Avaliação do desempenho térmico e luminoso de brise-soteils opacos e transparentes & Mestrado & Fapesp \\
\hline $2002 / 05$ & Fábio Luís Abreu & Marcelo Roméro & $\begin{array}{l}\text { Parâmetros climáticos para a arquitetura: o efeito de ilha de calor nas aglomeraçōes urbanas e } \\
\text { a definiçăa de um zoneamento climático para o estado de São Pau o }\end{array}$ & Mestrado & - \\
\hline 2002/05 & Juliana Bechara Saft & Marcelo Roméro & $\begin{array}{l}\text { Propriedades termofísicas de materiais e componentes na arquitetura dos setores comercial e } \\
\text { residencial no estado de Sã॰ Paulo }\end{array}$ & Mestrado & - \\
\hline 2003/06 & Juliano Beraldo & Marcelo Roméro & $\begin{array}{l}\text { Aferiçăo do algoritmo de cálculo de uma proposta de regulanento de eficiência energética para } \\
\text { o estado de Săo Pau o }\end{array}$ & Mestrado & Fapesp \\
\hline $2002 / 05$ & Marcelo Mendonça & Marcelo Roméro & Escritórios residenciais: espaço, comportamento e produtividade & Mestrado & - \\
\hline $2001 / 04$ & $\begin{array}{l}\text { R.cardo Laurentino } \\
\text { Vasconcelos }\end{array}$ & Marcelo Roméro & $\begin{array}{l}\text { Retrofit e eficiência energética: análise e eficiência energética e pay-back de investimentos } \\
\text { para retrofit, dos sistemas elétricos na ç dade de sāo Faulo, construídos na década de } 80\end{array}$ & Mestrado & - \\
\hline $2001 / 05$ & Maria Inés Lage de Paula & Marcelo Roméro & Gestão energética & Doutorado & - \\
\hline $2004 / 07$ & Gisele S. Benedetto & Marcelo Roméro & Consumo desagregado por usos finais no setor residencial em São Paulo & Mestrado & Nisam USP \\
\hline $2000 / 05$ & Ana Lúcia de A. Gonçalves & Marcelo Roméro & $\begin{array}{l}\text { A iluminação urbana nos centros históricos - adequação do projeto à ambiência. Uma } \\
\text { metodologia para planos diretores e projetos de iluminação. } 0 \text { caso de Paraty }\end{array}$ & Doutcrado & - \\
\hline $1998 / 03$ & Roberta Kronka Mulfarth & Uallrido Del Carlo & Arquitetura de baixo impacto humano e ambiental (concluida) & Doutorado & Fapesp \\
\hline $1998 / 03$ & Joana Carla S. Gonçalves & Ualfrido Del Carlo & $\begin{array}{l}\text { A sustentabilidade do edificic alto: uma geraçāo de edific os altos e sua inserçāo urbana } \\
\text { (concluida) }\end{array}$ & Doutorado & - \\
\hline $2004 / 07$ & José Ovidio Peres Ramos & Ualffido Del Carlo & Acústica de espaços urbanos em São Pau bo & Mestrado & - \\
\hline $2004 / 07$ & Andrea Vosgueritchian & Ualfrido Del Carlo & o processo de projeto de arqu tetura e a sustentabilidade & Mestrado & - \\
\hline $1996 / 00$ & Denise Helena Silva Duarte & Geraldo Gomes Serra & $\begin{array}{l}\begin{array}{l}\text { Padrōes de ocupaçāo do solo e microcl mas uroanos para a regiāo de clima tropical continental } \\
\text { (concluida) }\end{array} \\
\end{array}$ & Doutorado & Fapesp \\
\hline $2003 / 04$ & Gustavo Brunell: & $\begin{array}{l}\text { Joana Carla S. } \\
\text { Gonçalves }\end{array}$ & Conforto ambiental em edificios industriais & \begin{tabular}{l|l} 
Mestrado \\
AALondon \\
\end{tabular} & Alban (EC) \\
\hline $2003 / 04$ & Mônica Pereira Marcondes & $\begin{array}{l}\text { Joana Carlas. } \\
\text { Gonçalves }\end{array}$ & Eficiência energé tica de fachadas duplas & $\begin{array}{l}\text { Mestrado } \\
\text { AALondon }\end{array}$ & Alban (EC) \\
\hline $2004 / 07$ & D.mas Bertolottı & Paulo Scarazzato & Escolas sustentáveis em São Paulo: critérios de projeto & Mestrado & - \\
\hline $2004 / 07$ & Daniela Laudares & Paulo Scarazzato & $\begin{array}{l}\text { Modelos de avaliação dã iluminação natura para ed ficaçōes. Estudo comparativo por mediçōes } \\
\text { em ambientes reais, modelos fisicos em escala reduzida e simulaçōes computacionais }\end{array}$ & Mestrado & - \\
\hline $1999 / 05$ & Denise Dantas & Jorge Boueri & Novos métodos de projeto em design frente às novas tecnologias digitais & Doutorado & - \\
\hline $1999 / 04$ & Nilson Franco Martins & Jorge Boueri & A hierarquização viárla como tecnologia para as nterfaces urbano rodoviárias & Doutorado & - \\
\hline $2000 / 04$ & Tânia Pietzschke Abat & Jorge Boueri & $\begin{array}{l}\text { Dados antropométricos da infância e adolescênc a aplicados no dimensionamento do mobilírio } \\
\text { e dos equipamentos da habitaçăo }\end{array}$ & Mestrado & - \\
\hline $2000 / 05$ & Selso Da| Belo & Jorge Boueri & Arquitetura do ferro e do aço e o crescimento e desenvolvimento no Vale do Parába paulista & Doutorado & - \\
\hline $2001 / 05$ & $\begin{array}{l}\text { Adriana Vol pon Diogo } \\
\text { Righetto }\end{array}$ & Jorge Boueri & Evolu çắo do espaço tridimensional por meio do desentio & Doutorado & - \\
\hline $2001 / 05$ & $\begin{array}{l}\text { Suzy Maria C. Mariño } \\
\text { Pequini }\end{array}$ & Jarge Boueri & Aspectos ergonômicos na seleçâa e uso da bicic eta & Mestrado & - \\
\hline $2002 / 05$ & Alexandre Kenchian & Jorge Boueri & Modelos e técnicas de dimensionamento dos ambientes da habitaçäo & Mestrado & - \\
\hline $2003 / 06$ & Maria Valéria Affonso Lopes & Jorge Boueri & Adaptaçōes dimensionais dos ambientes da hab taçāo para cuidados com a saúde & Mestrado & - \\
\hline $2004 / 07$ & Claudia Maria L. Lapetina & Jorge Boueri & $\begin{array}{l}\text { Estudos dimensionais dos projetos d e apartamentos de } 4 \text { dormitórios da cidade de São Paulo } \\
\text { no iníc o do século } 21\end{array}$ & Mestrado & - \\
\hline
\end{tabular}

Fonte: Autora 


\section{Pesquisas de iniciaçÃo Científica}

As pesquisas em iniciação científica têm abordado estudos urbanos de conforto ambiental, com trabalhos de campo em São Paulo, simulação de insolação e iluminação com modelos físicos, caracterização térmica e luminosa de material têxtil para uso em coberturas e medições das condições de conforto em edifícios com simulações computacionais.

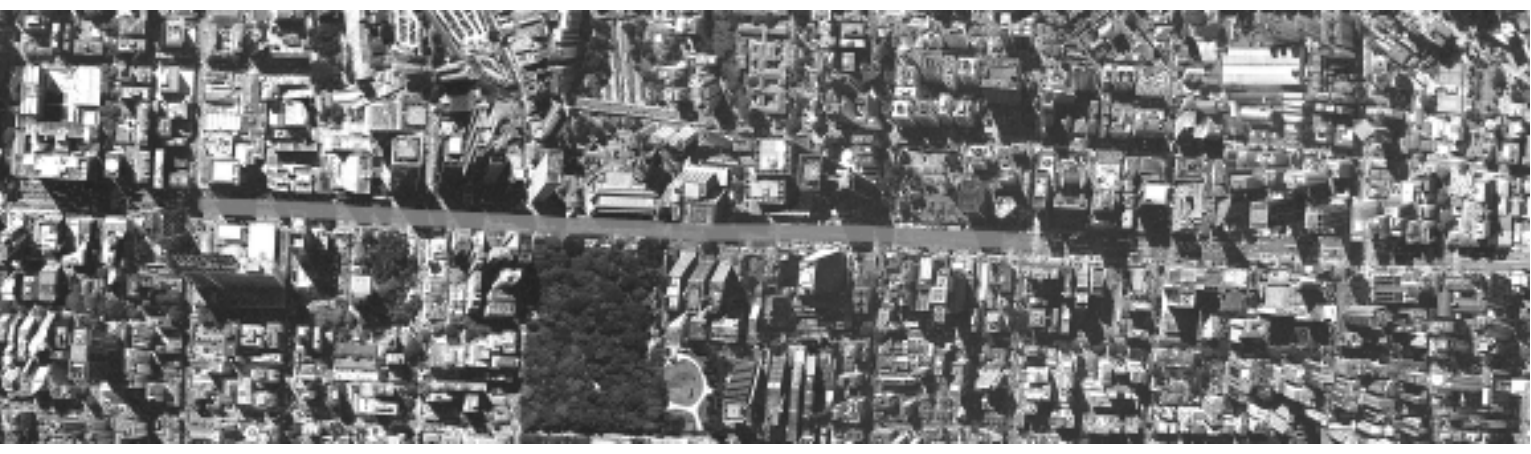

Figura 3 - Leitura e representação gráfica das condições ambientais urbanas. Estudo de caso: Avenida Paulista Fonte: Trabalho de iniciação científica de Tatiana M. de Souza
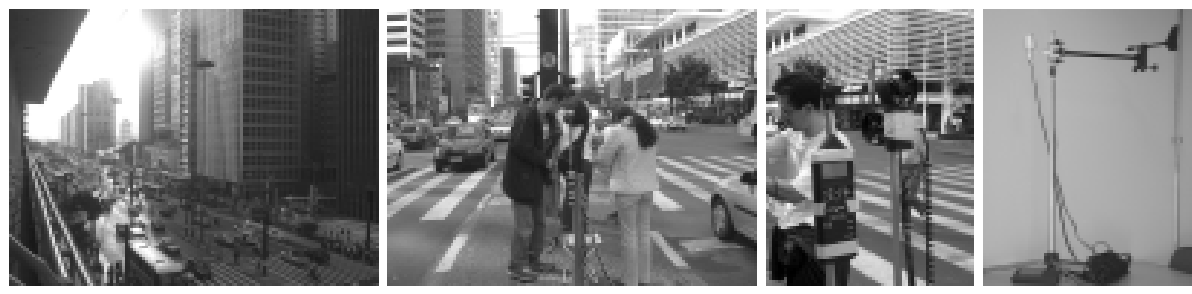

Tabela 2 - Pesquisas de iniciação científica vinculadas ao LABAUT

\begin{tabular}{|c|c|c|c|c|}
\hline & Aluno (a) & Orientador (a) & Título & Bolsa \\
\hline $2001 / 02$ & Fábio Faria & Anésia Frota & $\begin{array}{l}\text { Formas de garantir um conforto térmico ao usuário na cidade de São Pa ulo. Estudo de caso: } \\
\text { edif́cio CDHU (concluida) }\end{array}$ & Fapesp \\
\hline $2001 / 02$ & Cristina Mizuki Umetsu & Anésia Frota & $\begin{array}{l}\text { Formas de garantir um conforto térmico ao usuário na cidade de Sä́ Paulo. Estudo de caso: } \\
\text { unidade residencial unifamil iar CDHU (concluída) }\end{array}$ & Fapesp \\
\hline $1996 / 97$ & Celso Longo & Márcia Alucci & $\begin{array}{l}\text { Banco de dados de caracteristicas térmicas, acústicas e luminosas de vidros e policarbonatos } \\
\text { (concluída) }\end{array}$ & $\mathrm{P}|\mathrm{B}| \mathrm{C}$ \\
\hline $1996 / 97$ & Marcos Inoue & Márcia Alucci & $\begin{array}{l}\text { Banco de dados de caracteristicas térmicas, acústicas e luminosas de vidros e policar bonatos } \\
\text { (concluída) }\end{array}$ & Fapesp \\
\hline $2002 / 03$ & Paula Constante Santos & Márcia Alucci & Banco de dados de caracteristicas acústicas (concluida) & Fapesp \\
\hline $2002 / 03$ & Gabriela Audi Ferreira & Márcia Alucci & Banco de dados climáticos (concluida) & Fapesp \\
\hline $2002 / 03$ & Joāo Lu z Bellia & $\begin{array}{l}\text { Denise Duarte / Joana Carla S. } \\
\text { Gonçalves }\end{array}$ & $\begin{array}{l}\text { A influência da arquitetura no conforto luminoso de uma nova geraçâo de edificios altos de } \\
\text { escritór os no contexto internac onal (concluída) }\end{array}$ & $\mathrm{P} \mid \mathrm{BIC}$ \\
\hline $2003 / 04$ & Tatiana Moreira de Souza & Derise Duarte & $\begin{array}{l}\text { Leitura e representação gráfica das condições ambientais urbanas: Estudo de caso avenida } \\
\text { Paulista (concluida) }\end{array}$ & Fapesp \\
\hline $2003 / 04$ & Marisa Bueno e Souza & Denise Duarte / Reginaldo Ronconi & $\begin{array}{l}\text { Pesquisa, projeto e construçāo de ferramentas de ensaio para modelos físicos em conforto } \\
\text { ambiental : heliodon }\end{array}$ & $\mathrm{P} \mid \mathrm{BIC}$ \\
\hline $2003 / 05$ & Luciana Schwandner & Márcia Alucci & Estudo de iluminação natural de ed fícios através de modelos físicos em escala reduzida & $\mathrm{P}|\mathrm{B}| \mathrm{C}$ \\
\hline $2003 / 04$ & Kátia Zanellato & Reginaldo Ranconi / Márcia Alucci & $\begin{array}{l}\text { Pesquisa e ensaios de membranas e diretrize s para a otimização do processo de projeto das } \\
\text { tensoestruturas }\end{array}$ & $\mathrm{P}|\mathrm{B}| \mathrm{C}$ \\
\hline $2003 / 05$ & Bruna Luz & Paulo Scarazzato / Márcia Alucci & Estudo de i uminação natural de ed fícios por meio de modelos físicos em escala reduzida & Fapesp \\
\hline $2004 / 05$ & Rodrigo Cavalcante & Joana Carla S. Gonçalves & $\begin{array}{l}\text { Aval iaçăo do conforto têrm co do edifício da FAUUSP, C dade Universitária: mediçūes de } \\
\text { campo }\end{array}$ & $\mathrm{P}|\mathrm{B}| \mathrm{C}$ \\
\hline $2004 / 05$ & Patricia Mara Sanches & Joana Carla S. Gonçalves & $\begin{array}{l}\text { Aval iação do conforto térmi co do edificio da FAUUSP, C dade Universitária: simulaçōes } \\
\text { computacionais }\end{array}$ & Fapesp \\
\hline
\end{tabular}

Fonte: Autora 


\section{Apoio aos trabalhos finais de graduaÇão E ÀS PESQUISAS EXTERNAS}

O LABAUT disponibiliza apoio laboratorial aos trabalhos finais de graduação da FAUUSP, inclusive de outras linhas de pesquisa, e também às pesquisas externas. Foram feitos, por exemplo, ensaios em túnel de vento para auxiliar as decisões de projeto de um trabalho final de graduação, ensaios de transmitância térmica e luminosa por meio de membranas para alimentar as simulações de desempenho de coberturas têxteis, medições de clima externo e medições internas para avaliação pós-ocupação de um edifício de escritórios em São Paulo, e medições de conforto térmico e ventilação no edifício da FAUUSP para alimentar as simulações computacionais de uma dissertação de mestrado da University of Cambridge de uma ex-aluna da FAUUSP.
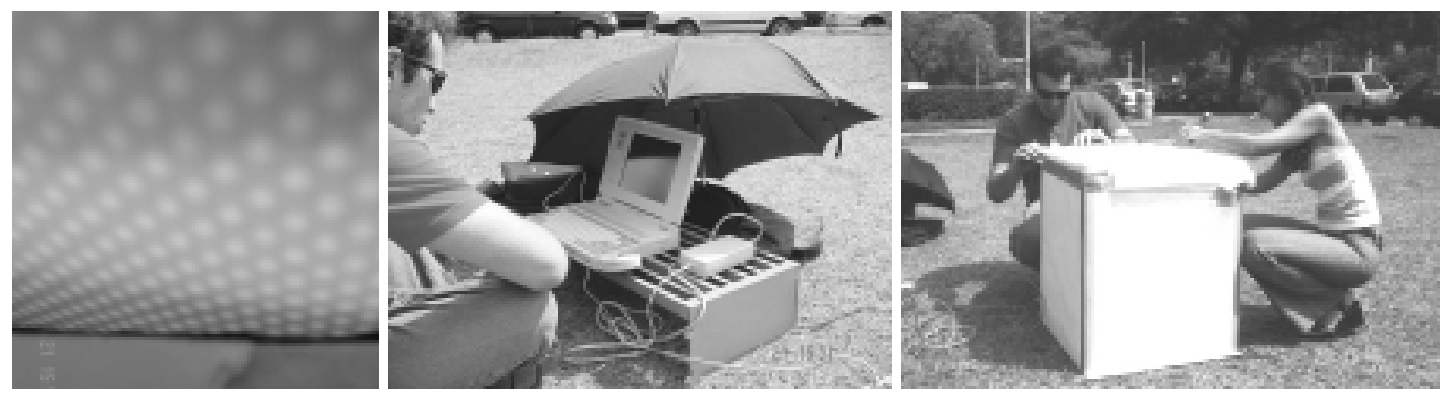

Figura 4 - Ensaio de transmissividade térmica e luminosa em cobertura têxtil

Fonte: TFG Mônica Marcondes - Centro de Tecnologia e Educação Ambiental
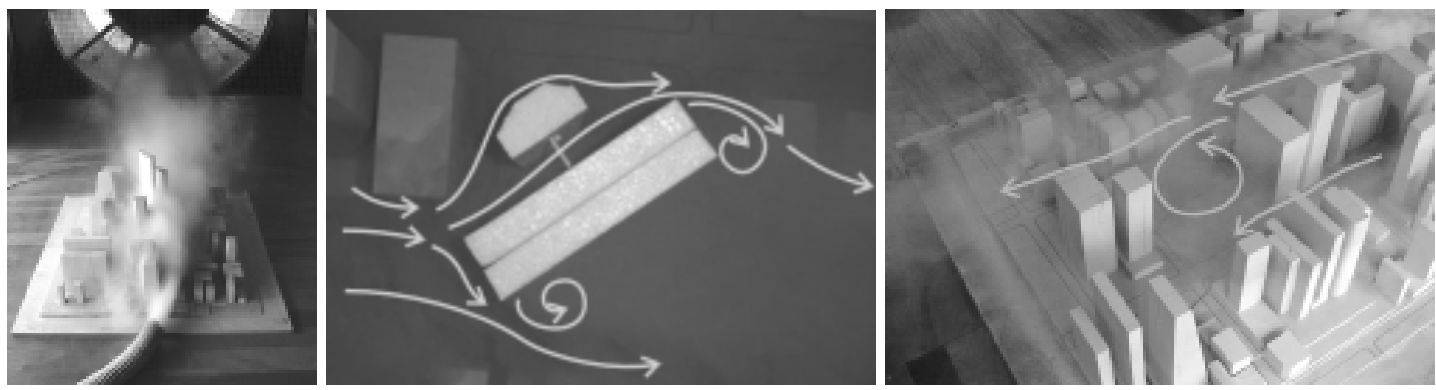

Figura 5 - Ensaio de impacto provocado por um edifício alto, no padrão de vento Fonte: TFG Thiago Hernandes - Projeto de Edifício Alto para São Paulo
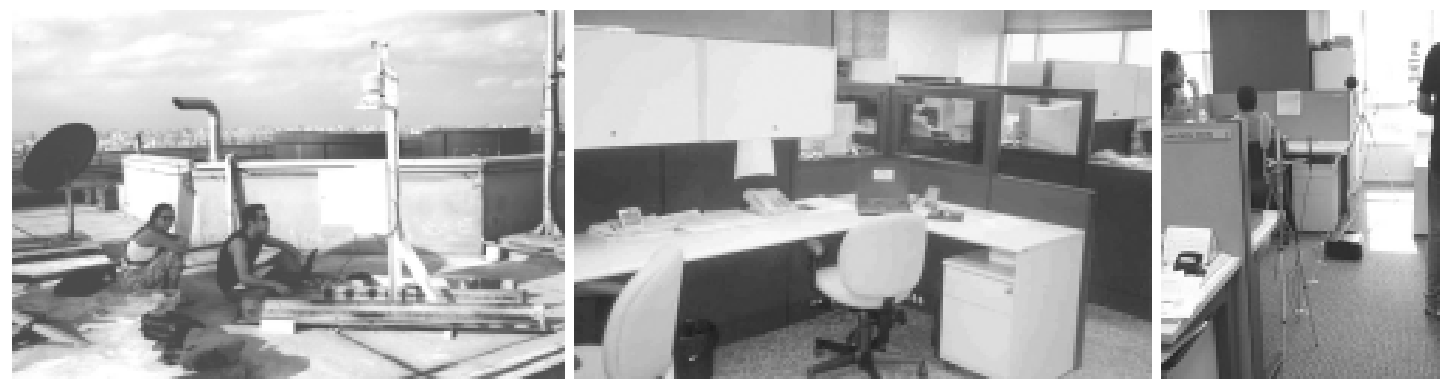

Figura 6 - Avaliação pós-ocupação de um edifício de escritórios em São Paulo Crédito: Acervo LABAUT 

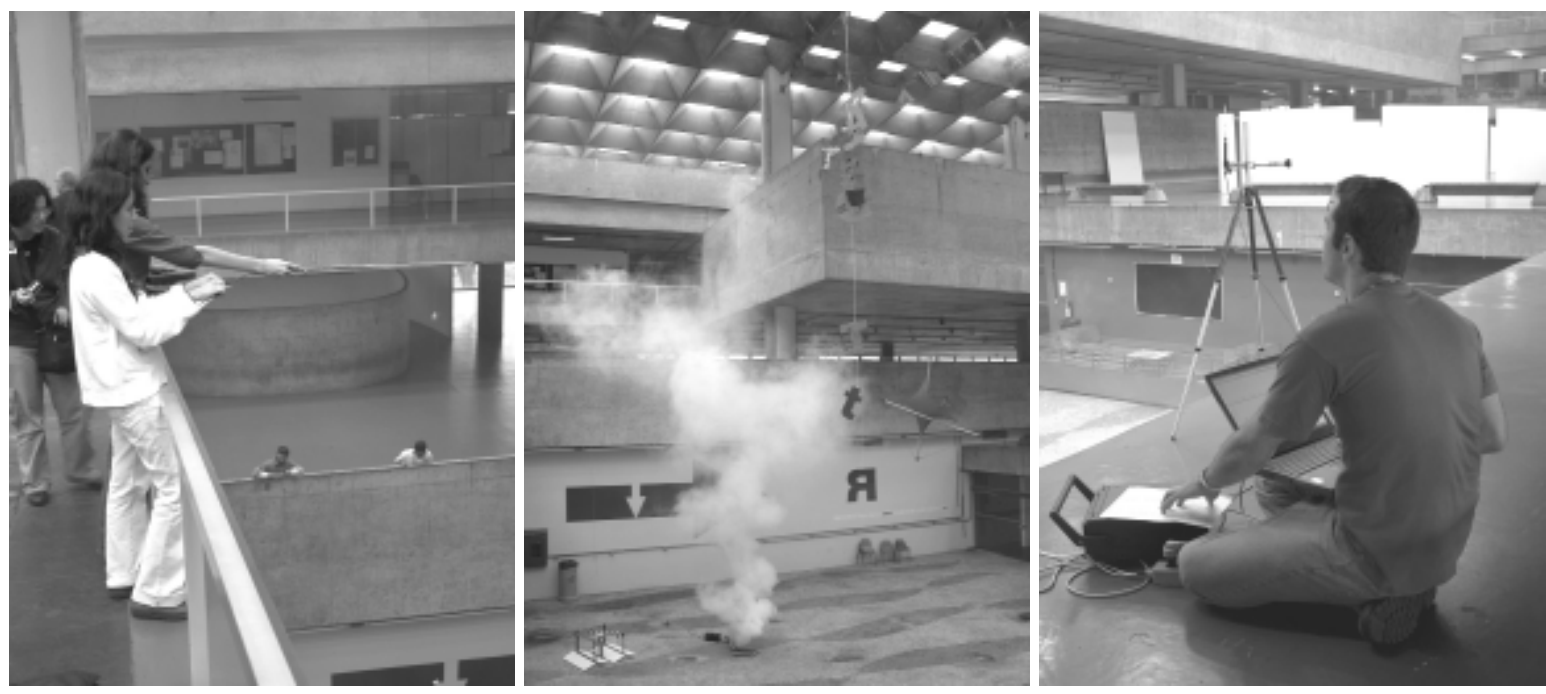

Figura 7 - Medições e ensaios de conforto ambiental no edifício da FAUUSP

Fonte: Mestrado de Filomena Russo/University of Cambridge

\section{Participação em eVentos, exposições, PREMIAÇÕES E PUBLICAÇÕES RECENTES}

Os pesquisadores do LABAUT vêm participando ativamente de eventos nacionais e internacionais de sua área de atuação, com apresentação, exposição e publicação de trabalhos de graduação (IC e TFG), pós-graduação e dos docentes, principalmente, Encontro Nacional de Conforto no Ambiente Construído - ENCAC -, Encontro Latino-Americano de Edificações e Comunidades Sustentáveis ELECS no Núcleo de Pesquisa em Tecnologia da Arquitetura e do Urbanismo NUTAU - e no Passive and Low Energy Architecture - PLEA desde 1998.

Os alunos de graduação tiveram participação em todas as edições da Bienal José Miguel Aroztegui (Concurso Estudantil Latino-Americano de Arquitetura Bioclimática), desde 1999, e a FAU recebe a Exposição Itinerante dos 12 melhores trabalhos a cada edição. Alguns trabalhos da graduação também foram expostos na mostra ArqSol, durante o ASADES - Energias Renovables y Ambiente. Promoción y Diseño de Sustentabilidad, na UBA, Buenos Aires, em 2002. Uma equipe do LABAUT também participou do concurso Bairro Novo, promovido recentemente pelo IAB/SP.

Em abril de 2004 aconteceu, no Museu da FAUUSP, a Expo LABAUT 2004, por ocasião dos dois anos de implementação do laboratório, com uma exposição de pôsteres de trabalhos de graduação (IC e TFG) e pós-graduação, pesquisas dos docentes, trabalhos de concursos, sendo alguns deles premiados no Brasil e no exterior, softwares desenvolvidos e livros publicados recentemente pelos integrantes da equipe.

No primeiro semestre de 2004 o LABAUT participou, como parte da equipe da Zanettini Arquitetura, do concurso nacional para o projeto do complexo CENPES II, promovido pela Petrobrás. Desse concurso participaram como convidados quatro importantes escritórios de arquitetura do país. O LABAUT participou desde a concepção inicial do projeto, fazendo a consultoria em eco- 
Figura 8 - Expo LABAUT 2004, Museu FAUUSP, em abril de 2004

Crédito: Acervo LABAUT
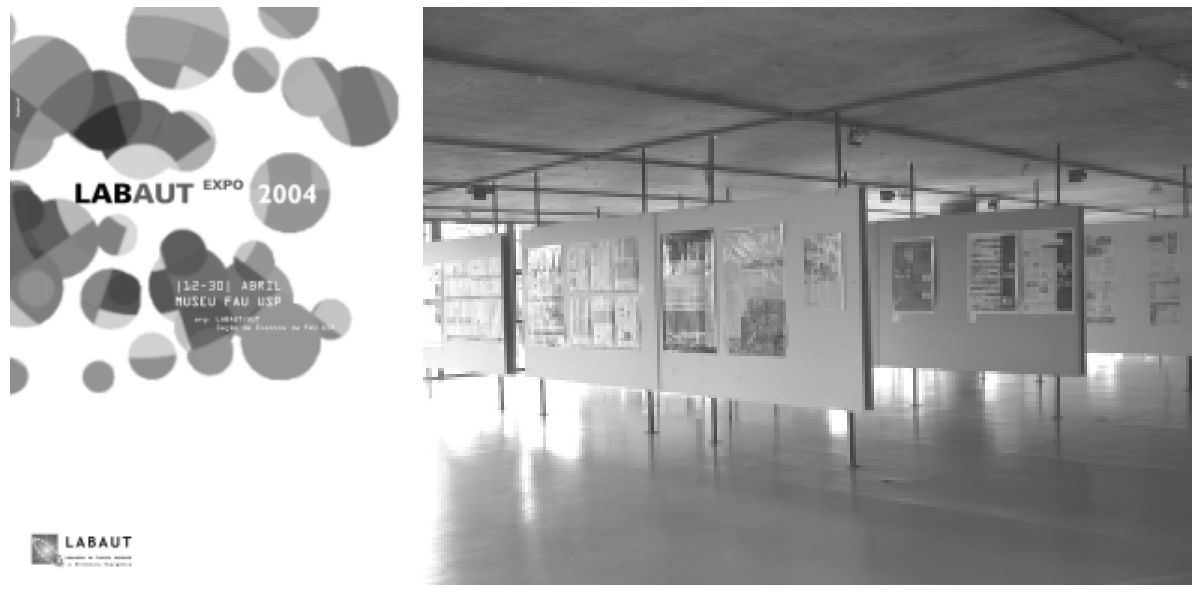

P. LABAUT



Figura 9 - Projeto Bairro Novo. Concurso IAB/SP. Equipe: Anna Chistina Miana, Cecílica Mueller, Daniela Weintraub, Denise Duarte, Fabio Faria, Joana Carla Gonçalves, Lene Nettelbeck, Marcos Rosa, Tatiana Souza, Vanessa Grossman. Consultoria: Ricardo Toledo - drenagem; Khaled Ghoubar custos; e Alessandra Prata - ventilação

Crédito: Acervo LABAUT

eficiência (térmica, acústica, iluminação natural e indicadores de impacto ambiental), exigidos em caráter eliminatório no edital do concurso. O CENPES II vai duplicar as atuais instalações de pesquisa e desenvolvimento da empresa, e a meta da Petrobrás é que este projeto traga uma mudança de paradigma destacando as questões de conforto, energia e meio ambiente para a arquitetura brasileira.

As publicações recentes da equipe incluem:

- ROMÉRO, Marcelo de Andrade; PHILIPPI Jr., A.; ALVES, A. C.; BRUNA, C. G. Meio ambiente, direito e cidadania. São Paulo: Signus, p. 358, 12 mar. 2002.

- FROTA, Anésia. Geometria da insolação. São Paulo: Geros, 2004.

- VIANNA, Nelson Solano; GONÇALVES, Joana. Iluminação e arquitetura. São Paulo: Virtus, 2001.

- Cadernos do LABAUT, n.1. Arquitetura, tecnologia e ambiente em exercícios de projeto (no prelo). Esta publicação tem por objetivo divulgar exercícios de projeto realizados como trabalhos de disciplina, trabalhos finais de graduação e concursos nacionais e internacionais com foco nas áreas de conforto, eficiência energética e impacto ambiental do ambiente construído. 


\section{Projetos futuros}

\subsection{Ampliar o laboratório didático}

O LABAUT desenvolve uma linha de pesquisa com o Laboratório de Modelos e Ensaios - LAME, coordenado pelo Prof. Dr. Reginaldo Ronconi, também do AUT, particularmente voltada para os alunos de iniciação científica. Essa linha tem por objetivos a pesquisa, o projeto e a construção de ferramentas de ensaio para modelos físicos em conforto ambiental, de modo a permitir o ensaio em maquetes. A construção do heliodon em arco (em andamento) já foi mais um passo; o próximo é a construção de um túnel de vento simplificado. Entre as vantagens da utilização de simulação experimental por meio de modelos físicos estão:

- A adequação para condições de formas complexas;

- a facilidade de comparação entre soluções alternativas de projeto, por componentes intercambiáveis, permitindo, ainda, avaliações quantitativas e qualitativas;

- a utilidade na validação de modelos computacionais;

- a familiarização para a maioria dos projetistas, estimulando a percepção e compreensão dos fenômenos físicos envolvidos;

- a utilização como instrumento de comunicação entre membros da equipe de projeto e/ou entre projetista e cliente.

\subsection{Ampliar o laboratório de pesquisas para edifícios}

Está em discussão um projeto de pesquisa para a construção de uma câmara de ensaio para simulação de diferentes tipos de fachada, que permita a alteração dos componentes construtivos e da configuração do modelo, com monitoramento interno de todas as variáveis envolvidas.

\subsection{Ampliar os estudos de conforto ambiental urbano}

Está em discussão um projeto de pesquisa envolvendo outras áreas do conhecimento para requalificação de áreas urbanas, em especial a região central de São Paulo. A idéia é aplicar os resultados já obtidos em ventilação urbana, acesso solar, microclimas urbanos, estendendo o campo de atuação para outras questões ambientais.

\subsection{Atualizar e ampliar a capacitação da equipe em simulação computacional}

Já está em andamento um treinamento intensivo da equipe com os mais novos softwares de simulação de desempenho térmico, acústico e luminoso disponíveis hoje, graças à recente aquisição de licenças pelo LABAUT. Esses programas são fundamentais para agilizar os trabalhos e agregam maior sofisticação às simulações, que permitem geometrias mais complexas e saídas com visualizações mais amigáveis para o usuário. 


\subsection{Ampliar o relacionamento internacional}

O contato com o Laboratório Nacional de Engenharia Civil - LNEC -, em Lisboa, existe há muitos anos com o Departamento de Tecnologia da Arquitetura da FAUUSP, e vem gerando novos frutos. Em 2004, o Prof. Dr. Jorge Gil Saraiva orientou o trabalho experimental no túnel de vento da aluna Alessandra Prata durante seu "doutorado sanduíche", acompanhado também pela Prof. Dra. Anésia Frota.

A cooperação internacional com a Inglaterra iniciou-se com o "doutorado sanduíche" da Prof. Dra. Joana Gonçalves na AA - Architectural Association Graduate School, em Londres, em 2001, e continuou com sua passagem como professora visitante em 2004. Atualmente a professora é co-orientadora de dois exalunos da FAUUSP no programa de mestrado Environment and Energy, na mesma instituição. Outro importante contato internacional é com o escritório de conforto ambiental e eficiência energética BDSP Partnership, por intermédio de seu diretor, engenheiro Klaus Bode, também professor visitante da AA, e colaborador na pesquisa de doutorado da professora Joana Carla Gonçalves. O NUTAU'2004, realizado entre 11 e 15 de outubro deste ano, trouxe como palestrantes convidados do painel de conforto e energia, coordenado pela Profa. Dra. Denise Duarte, o engenheiro Klaus Bode, a professora Susannah Hagan, da University of East London, e também o professor Koen Steemers, do Martin Centre, University of Cambridge. $\mathrm{O}$ contato com Cambridge teve início no apoio do LABAUT à pesquisa de mestrado da ex-aluna da FAUUSP, Filomena Russo, sob a orientação do professor Koen Steemers.

A participação dos pesquisadores do LABAUT em eventos internacionais, particularmente no PLEA, tem trazido excelentes contatos, que se renovam e ampliam-se a cada ano. Na edição de 2003, que aconteceu em novembro em Santiago do Chile, foram apresentados oito trabalhos da FAUUSP, sendo cinco deles resultados de trabalhos finais de graduação. Na edição 2004, realizado de 19 a 22 de setembro, em Eindhoven, Holanda participaram as Profas. Dras. Denise Duarte e Joana Carla Soares Gonçalves e o ex-aluno Luciano Caruggi de Faria, apresentando alguns trabalhos do grupo a envolverem também a Profa. Dra. Márcia Alucci, o Prof. Dr. Marcelo Roméro, os alunos da pós-graduação Alessandra Prata, Rafael Brandão e Leonardo Monteiro, e a aluna de graduação Tatiana Moreira de Souza.

As pesquisas mais recentes vêm contando com contribuições relevantes de pesquisadores e profissionais atuantes no cenário internacional, na área de conforto ambiental e energia, tais como: Baruch Givoni, o qual esteve na FAUUSP como palestrante convidado do NUTAU'2000, Ken Yeang, Simos Yannas e outros. A participação dos membros da equipe do LABAUT em eventos internacionais e a vinda de pesquisadores externos é parte integrante dos projetos futuros do laboratório.

\section{Denise Duarte}

Professora do Departamento de Tecnologia da Arquitetura da FAUUSP e pesquisadora do LABAUT. 